\title{
Arm span-height difference is correlated with gastroesophageal reflux symptoms in aged Japanese subjects
}

\author{
Hitoshi Eguchi, ${ }^{1}$ Yuichiro Eguchi, ${ }^{2, *}$ Motoshi Fujiwara, ${ }^{1}$ Midori Nishii, ${ }^{1}$ Yoshinori Tokushima, ${ }^{3}$ Naoko Eguchi, ${ }^{1}$ \\ Masaki Tago, ${ }^{1}$ Yuta Sakanishi, ${ }^{3}$ Motosuke Tomonaga, ${ }^{1}$ Tsuneaki Yoshioka, ${ }^{1}$ Masaki Hyakutake, ${ }^{1}$ Sei Emura, ${ }^{1}$ \\ Shunzo Koizumi, ${ }^{1}$ Ryuichi Iwakiri, ${ }^{4}$ Genichiro Edakuni, ${ }^{5}$ Masamichi Oda, ${ }^{6}$ Katsuma Hiramatsu, ${ }^{7}$ \\ Kazuma Fujimoto, ${ }^{4}$ Takashi Sugioka ${ }^{3}$ and Shuichi Yamashita ${ }^{1}$ \\ 'Department of General Medicine, Saga Medical School, ${ }^{2}$ Department of Liver Disease Control and Assistance, Saga Medical School, \\ ${ }^{3}$ Community Medical Support Institute and ${ }^{4}$ Department of Internal Medicine, Saga Medical School, 5-1-1 Nabeshima, Saga, Saga 849-8501, Japan \\ ${ }^{5}$ Edakuni Hospital, 265 Hayatsue, Kawasoemachi, Saga, Saga 840-2203, Japan \\ ${ }^{6}$ Oda Hospital, Kashima, 4306 Oaza-takatsuhara, Kashima, Saga 840-1392, Japan \\ ${ }^{7}$ Hiramatsu Hospital, 815-1 Ogimachi, Ogi, Saga 845-0001, Japan
}

(Received 15 August, 2012; Accepted 17 September, 2012; Published online 14 November, 2012)

Previous studies have indicated an association between the symptoms of gastroesophageal reflux disease (GERD) and aging plus height. In this study we investigated whether the arm spanheight difference was related to GERD symptoms with a focus on aged subjects in the general population, since the arm span reflects the height in young adulthood before decreasing due to vertebral deformities from aging. A total of 285 elderly individuals (105 females) who visited nursing homes for the elderly in Japan were enrolled in this study. The GERD symptoms were evaluated by the Frequency Scale for the Symptoms of GERD (FSSG). The body weight, height and arm span were measured, and information regarding medications and complications were reviewed in each nursing record. $50.5 \%$ of women had more than $3 \mathrm{~cm}$ of arm span-height difference. In contrast, only $37.3 \%$ of men had more than $3 \mathrm{~cm}$ of arm span-height difference. The FSSG scores indicated more than $70 \%$ of subjects complained of any GERD symptoms. There was a significant correlation between the FSSG score and the arm span-height difference in the subjects with more than $3 \mathrm{~cm}$ of arm span-height difference $(r=0.236 ; p=0.012)$. The correlation between the arm span-height difference and the FSSG score was significant only in women in females in the present study. In conclusion, our findings indicate that vertebral deformity evaluated by the arm span-height difference might have some positive relationship to the pathogenesis of GERD symptoms in elderly Japanese individuals.

Key Words: aging, kyphosis, orthopedics, sex difference, vertebral deformities

recent study showed that lifestyle including a westernized diet, ${ }^{(1)}$ obesity and alcohol beverage ${ }^{(2-4)}$ were risk factors contributing to the development of gastroesophageal reflux disease (GERD) in Japan. Some reports indicated that aging, kyphosis and/or low height were risk factors for GERD. ${ }^{(5,6)}$ The arm span reflects the height in young adults at around 20 years of age, ${ }^{(7)}$ and the arm span-current height difference indicates loss of height from that of young adulthood because of vertebral deformities.

Previous studies demonstrated that the patients of GERD and/or non-erosive esophageal reflux disease patients complained of various upper gastrointestinal symptoms and that the frequencies of these symptoms were not proportional to the severity of endoscopic reflux esophagitis. ${ }^{(8-14)}$ The GERD symptoms have been evaluated using several questionnaires, including the Frequency
Scale for the Symptoms of GERD (FSSG). ${ }^{(15)}$ The FSSG is a GERD-specific questionnaire developed in Japan, and is used for screening of GERD patients.

Although many studies focused only on patients visiting medical facilities, there may be elderly individuals who experience upper gastrointestinal symptoms in the general population. Few studies have focused on their clinical symptoms in spite of the fact that many of the elderly individuals have risk factors for a high prevalence of GERD. ${ }^{\left({ }^{8}-11\right)}$ The aim of this study was evaluating the relationship between the arm span-height difference and GERD symptoms in aged subjects in the general population being treated in nursing homes for the elderly. The present study might show that the same is true in the general population as previous evidence obtained by hospital-based trials that old age and/or low height are risk factors for GERD.

\section{Methods}

Subjects. This study included 289 elderly individuals (age range: $55-100$ years; mean age: $83.4 \pm 7.3$ years) who visited nursing homes for the elderly, comprising 6 facilities in Saga prefecture in Japan, Mikazuki, Yuai Village, Kaede, Maple House, Kiyomizuen and Amigia, from May 2010 to March 2011. Informed consent was obtained from all subjects. The present study was conducted under protocol approval from the Ethical Committees of Saga Medical School.

The gastrointestinal symptoms were researched using the FSSG questionnaire. $^{(15)}$ The FSSG is a GERD-specific questionnaire developed in Japan and used for screening of GERD. The FSSG consists of 12 questions, comprising five questions regarding acid reflux-related symptoms and seven questions regarding dyspeptic symptoms, as shown in Fig. 1. The total score of the FSSG was used for evaluation, and scores of $\geq 8$ were diagnosed as symptomatic GERD. ${ }^{(15)}$ Detection of the FSSG was difficult in individuals without any support in the present study, and all were questioned vocally by the staff of the facilities using a loudspeaker and a screen on which the FSSG was projected. It took about one minute on each of the 12 questions of the FSSG. Finally, the FSSG scores were successfully obtained 285 of 289 subjects, and the remaining four subjects were omitted from the study. The body

*To whom correspondence should be addressed.

E-mail: eguchiyu@me.com 


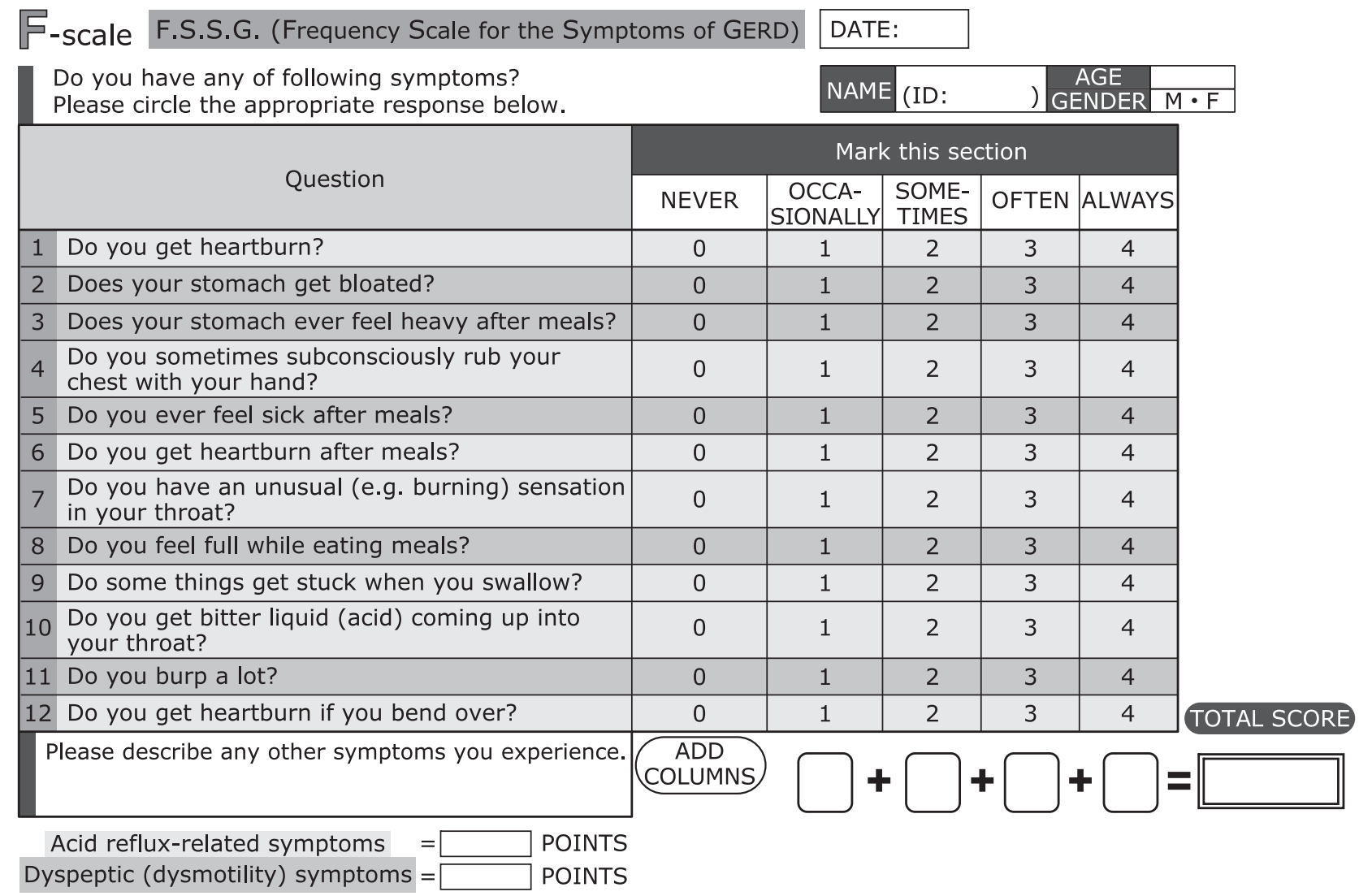

Fig. 1. The FSSG used in this study. When the scale was used in the study, all the characters were indicated in Japanese.

weight and height were measured in each subject, and the body mass index $\left(\mathrm{BMI}, \mathrm{kg} / \mathrm{m}^{2}\right)$ was calculated. The degree of spine shortening was defined as the difference between the arm span (in centimeters) and body height (centimeters), because the arm span was almost equivalent to the adolescent height in each person. The arm span was measured between the middle finger tips when the both arms were spread horizontally. The difference between the arm span and the measured height indicated loss of height from the adolescent height. In a previous study, subjects with arm span-height differences of $\geq 3 \mathrm{~cm}$ were frequently complicated with osteoporosis and vertebral deformities. ${ }^{(16)}$ Information of the present subjects, including medication and complications, was obtained from the charts in each nursing homes for the elderly.

Statistical analysis. The results were expressed as the mean \pm SD for each group. Statistical analyses, including the $\chi^{2}-$ test, were carried out using Statistical Analysis System software version 9.1 (SAS Institute, Cary, NC). Differences between two groups were compared by the Mann-Whitney $U$ test. Differences with values of $p<0.05$ were considered to show statistical significance.

\section{Results}

Characteristics of the subjects. The characteristics of the 285 subjects are summarized in Table 1 . The mean age was higher in women than in men $(84.1 \pm 7.1$ vs $81.4 \pm 7.7$ years; $p<0.01)$. Both the body weight and height were larger in men than in women $(p<0.01$ for each), while the BMI did not differ between men and women. The mean arm span-height difference in the total subjects was $2.86 \pm 6.7 \mathrm{~cm}$. The arm span-height difference, indicating shortened height in older age, was significantly higher in women than in men $(3.63 \pm 6.3$ vs $1.05 \pm 7.1 \mathrm{~cm}, p<0.01)$. More than half of the female subjects $(135 ; 50.5 \%)$ had arm span-height differences of $\geq 3 \mathrm{~cm}$, indicating an increased risk of complications of osteoporosis and vertebral deformities based on the previously reported criterion of $\geq 3 \mathrm{~cm}$. ${ }^{(16)}$

Regarding the FSSG, 56 of 285 individuals (19.6\%) had significant GERD symptoms (FSSG score $\geq 8$ ), as indicated in the original publication, ${ }^{(15)}$ and $141(49.4 \%)$ had GERD symptoms but with scores of $<7$. Therefore, a total of 197 individuals $(69 \%)$ had some GERD symptoms, and only 88 subjects $(30.9 \%)$ had no complaints of GERD symptoms. The mean of the total score of the FSSG as well as the acid reflux and functional dyspepsia scores did not differ between men and women.

Correlation between the arm span-height difference and FSSG score. Fig. 2 shows the relationship between the arm span-height difference and FSSG score in all 113 subjects with an arm span-height difference of $\geq 3 \mathrm{~cm}$. There was significant correlation between the FSSG score and an arm span-height difference of $\geq 3 \mathrm{~cm}(r=0.236 ; p=0.012)$. No correlation between the arm span-height difference and FSSG score was observed in the subjects with an arm span-height difference of $<3 \mathrm{~cm}$ (Fig. 3; $r=-0.019 ; p=0.826)$. These findings indicate that subjects with an arm span-height difference of $\geq 3 \mathrm{~cm}$ had more GERD symptoms than the subjects with an arm span-height difference of $<3 \mathrm{~cm}$. According to the separate analysis about sex, the relationship between the arm span-height difference and FSSG score in subjects with an arm span-height difference of $\geq 3 \mathrm{~cm}$ was observed in women (Fig. $4 ; r=0.227 ; p=0.033$ ). Men did not show such a significant difference (Fig. $5 ; r=0.092, p=0.438$ ). 
Table 1. Characteristics of the subjects in the present study

\begin{tabular}{lcccc}
\hline & $\begin{array}{c}\text { Total } \\
(n=285)\end{array}$ & $\begin{array}{c}\text { Males } \\
(n=81)\end{array}$ & $\begin{array}{c}\text { Females } \\
(n=204)\end{array}$ & $p$ value \\
\hline Age (years) & $83.3 \pm 7.4$ & $81.4 \pm 7.7$ & $84.1 \pm 7.1$ & 0.005 \\
& & $59-98$ & $55-100$ & \\
Weight $(\mathrm{kg})$ & $48.3 \pm 11.1$ & $57.8 \pm 9.7$ & $44.6 \pm 9.3$ & $<0.0001$ \\
BMI $\left(\mathrm{kg} / \mathrm{m}^{2}\right)$ & $21.7 \pm 3.9$ & $22.2 \pm 3.5$ & $21.5 \pm 4.0$ & 0.162 \\
AHD $(\mathrm{cm})$ & $2.86 \pm 6.7$ & $1.05 \pm 7.1$ & $3.58 \pm 6.4$ & 0.006 \\
AHD of $\geq 3 \mathrm{~cm}(\%)$ & 46.7 & 37 & 50.5 & 0.038 \\
FSS & $4.8 \pm 6.4$ & $4.79 \pm 6.5$ & $4.8 \pm 6.4$ & 0.987 \\
ARS & $2.69 \pm 4.0$ & $2.77 \pm 4.0$ & $2.66 \pm 4.0$ & 0.837 \\
FDS & $2.12 \pm 2.8$ & $2.02 \pm 2.9$ & $2.15 \pm 2.8$ & 0.729 \\
FSSG of $\geq 8(\%)$ & 20.7 & 17.3 & 22.1 & 0.37 \\
\hline
\end{tabular}

BMI, body mass index; ADH, arm span-height difference; FSSG, frequency scale for the symptoms of GERD; ARS, acid reflux score; FDS, functional dyspepsia score.

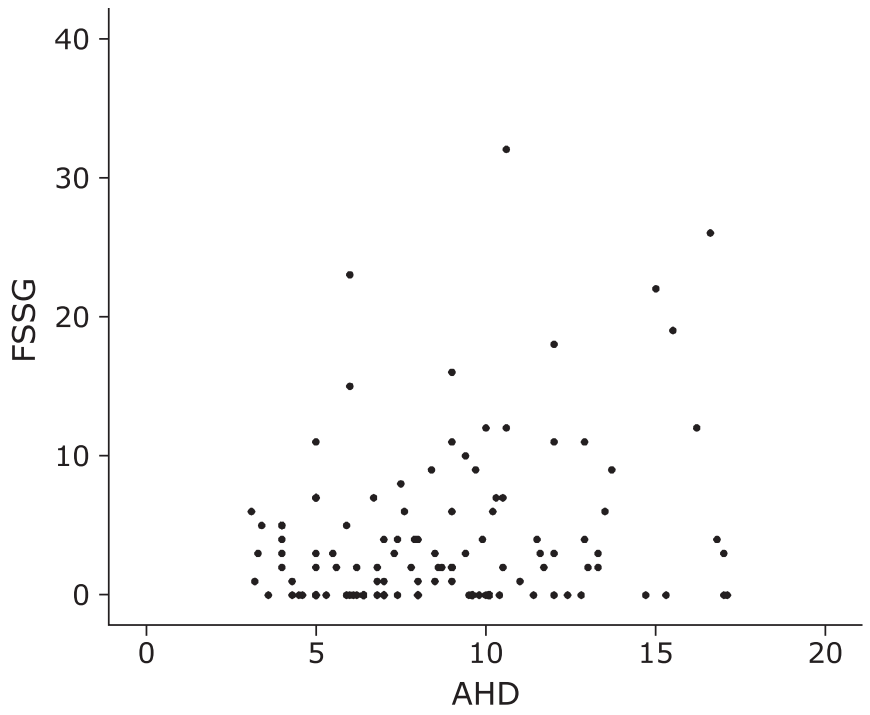

Fig. 2. Relationship between the FSSG score and an arm span-height difference of $\geq 3 \mathrm{~cm}$ in all 113 subjects.

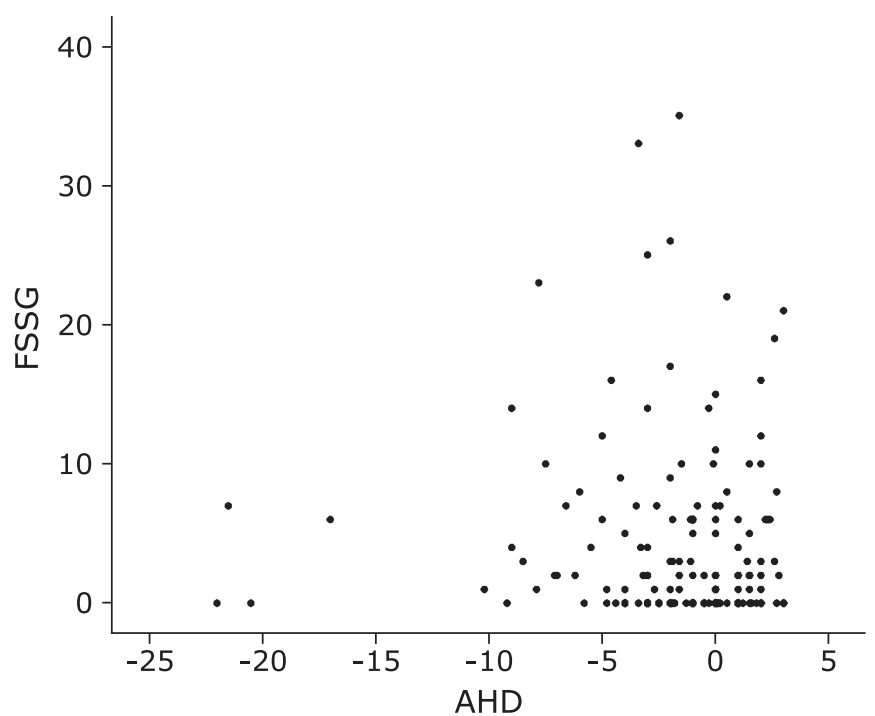

Fig. 3. Relationship between the FSSG score and an arm span-height difference of $<3 \mathrm{~cm}$ in all 137 subjects.

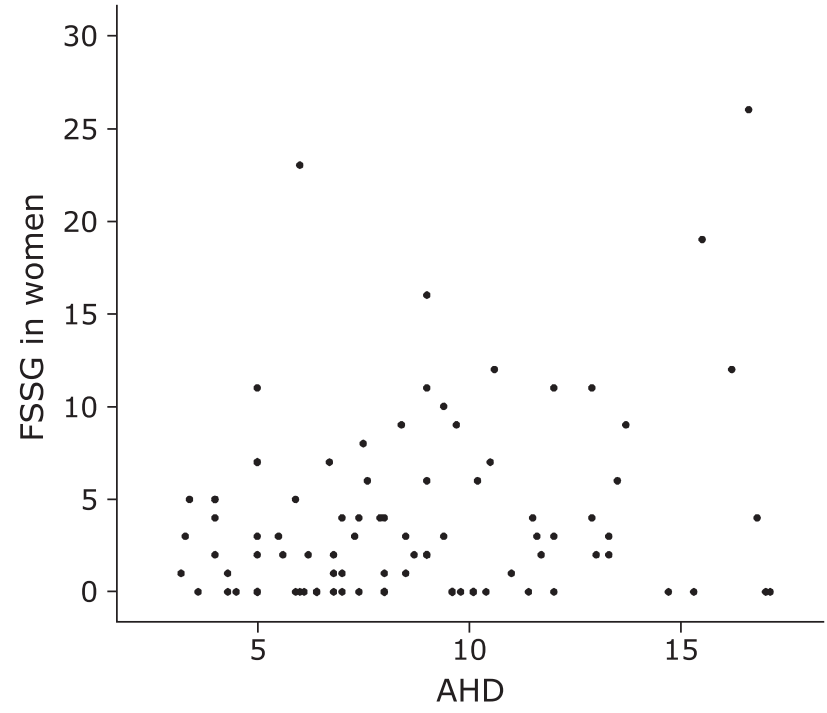

Fig. 4. Relationship between the FSSG and an arm span-height difference of $\geq 3 \mathrm{~cm}$ in all 180 women.

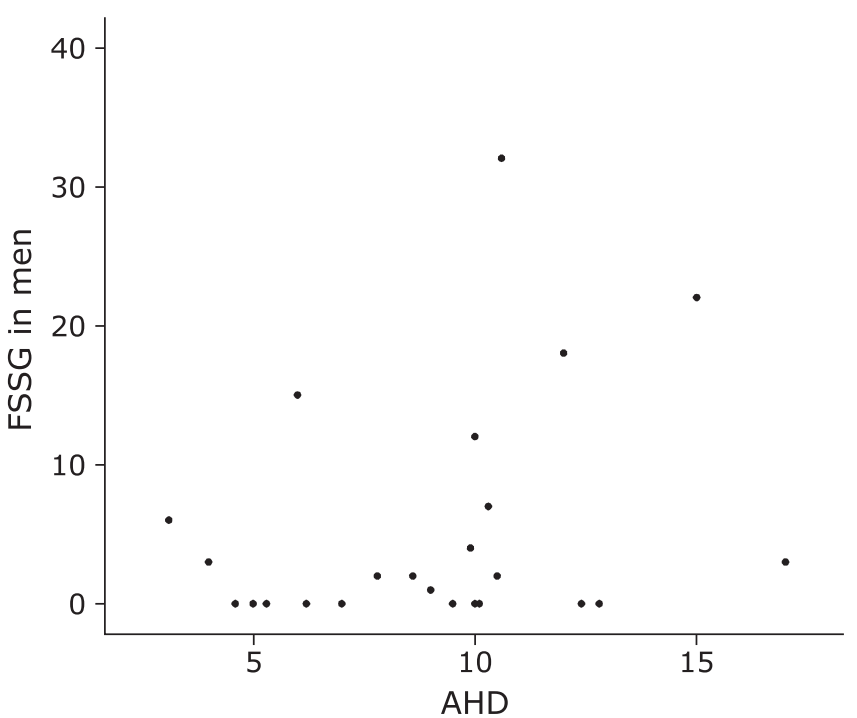

Fig. 5. Relationship between the FSSG score and an arm span-height difference of $\geq 3 \mathrm{~cm}$ in all 73 men. 


\section{Discussion}

This study have revealed a correlation between the FSSG score and arm span-height difference in aged Japanese subjects, indicating that a decrease in height might be an indicator for complications of GERD. Since the arm span was correlated with height in young adults aged around 20 years. ${ }^{(6,7)}$ This association might arise through complications of vertebral deformities, which can result in hiatal hernia and GERD in aged Japanese people. ${ }^{(17)}$ The data for the present study were obtained in nursing homes for the elderly in Japan in which endoscopic examination and checking for Helicobacter pylori infection was extremely difficult to be performed. There were two major advantages in the present study: i) the difference between arm span and height was measured easily even in the nursing house not in the hospital, and ii) the arm span difference was reproductive and a reliable marker for detection of GERD.

The present study has demonstrated a correlation between an arm span-height difference of $\geq 3 \mathrm{~cm}$ and the FSSG acid reflux score only in women. The previous reports in Japan demonstrated prevalence of GERD increased in elder females, ${ }^{(9-11)}$ whereas prevalence of GERD was not different between males and females reported from Western counties. ${ }^{(5)}$ High complication rate of kyphosis and hiatal hernia in aged Japanese females might be one of explanation for increase in GERD. ${ }^{(18-21)}$ These date explained partly the sex difference in this study. In addition, the sex difference might be partly explained by a previous study showing that men tended to have spur formation, while females tended to have flattened discs in their spines. ${ }^{(22)}$ Previous studies reported that an arm span-height difference of $\geq 3 \mathrm{~cm}^{(6)}$ or $\geq 5 \mathrm{~cm}^{(7)}$ reflected the vertebral deformity of kyphosis mainly in women. Another study reported a relationship between kyphosis and hiatus hernia plus GERD. ${ }^{(17)}$ In elderly Japanese subjects, radiographic lumbar

\section{References}

1 Bujanda L, Cosme A, Muro N, Gutiérrez-Stampa Mde L. Influence of lifestyle in patients with gastroesophageal reflux disease. Med Clin (Barc) 2007; 128: $550-554$.

2 Sonnenberg A. Effects of environment and lifestyle on gastroesophageal reflux disease. Dig Dis 2011; 29: 229-234.

3 Festi D, Scaioli E, Baldi F, et al. Body weight, lifestyle, dietary habits and gastroesophageal reflux disease. World J Gastroenterol 2009; 15: 1690-1701.

4 Boguradzka A, Tarnowski W, Cabaj H. Gastroesophageal reflux in alcoholabusing patients. Pol Arch Med Wewn 2011; 121: 230-236.

5 van Herwaarden MA, Samsom M, Smout AJ. The role of hiatus hernia in gastro-oesophageal reflux disease. Eur J Gastroenterol Hepatol 2004; 16: $831-835$.

6 Yoshimura M, Nagahara A, Ohtaka K, et al. Presence of vertebral fracture is highly associated with hiatal hernia and reflux esophagitis in Japanese elderly people. Intern Med 2008; 47: 1451-1455.

7 Tamaki J, Iki M, Kadowaki E, et al. Arm span increases predictive value of models for prevalent vertebral deformities: the Japanese Population-based Osteoporosis (JPOS) Study. Maturitas 2009; 64: 241-245.

8 Fock KM, Talley NJ, Fass R, et al. Asia-Pacific consensus on the management of gastroesophageal reflux disease: update. J Gastroenterol Hepatol 2008; 23: 8-22.

9 Fujiwara Y, Arakawa T. Epidemiology and clinical characteristics of GERD in the Japanese population. J Gastroenterol 2009; 44: 518-534.

10 Kinoshita Y, Adachi K, Hongo M, Haruma K. Systematic review of the epidemiology of gastroesophageal reflux disease in Japan. J Gastroenterol 2011; 46: 1092-1103.

11 Fujimoto K. Prevalence and epidemiology of gastro-esophageal reflux disease in Japan. Aliment Pharmacol Ther 2004; 20 (Suppl 8): 5-8.

12 Klauser AG, Schindlbeck NE, Müller-Lissner SA. Symptoms in gastrooesophageal reflux disease. Lancet 1990; 27: 205-208.

13 Miwa H, Sasaki M, Furuta T, et al. Efficacy of rabeprazole on heartburn symptom resolution in patients with non-erosive and erosive gastro-oesophageal reflux disease: a multicenter study from Japan. Aliment Pharmacol Ther spondylosis and/or vertebral fracture were intimately associated with hiatal hernia and reflux esophagitis. ${ }^{(17)}$ These studies support the present result of a relationship between an arm span-height difference of $\geq 3 \mathrm{~cm}$ and the FSSG acid reflux score in elder females.

The detection rate gastroesophageal symptoms by the FSSG reached $69 \%$ in the elderly subjects in this study. There have been a few reports describing relationships between gastroesophageal reflux and age, including increases in GERD in the perimenopausal or menopausal period, ${ }^{(23)}$ age-related decreases in sensorimotor response to esophageal acidification ${ }^{(24)}$ and impaired esophageal clearance owing to age-related degradation of the gastroesophageal junction. ${ }^{(25)}$ The high rate of reflux symptoms may not be clinically linked with the diagnosis and treatment of GERD in aged individuals, since a previous report suggested that the diagnosis of GERD was later in elderly individuals than in younger individuals. ${ }^{(26,27)}$

In conclusion, this study has clearly demonstrated a positive relationship between upper gastrointestinal symptoms and decreased height in elderly Japanese subjects, especially women.

\section{Acknowledgments}

The authors would like to thank Ms. Hisae Ariki, Ms. Ikuko Hirotaki, all the staff in Saga Medical School Hospital, the nursing homes for the elderly at Mikazuki, Yuai Village, Kaede, Maple House, Kiyomizuen and Amigia, and Mr. Takuya Sawada for assistance.

\section{Conflict of Interest}

No potential conflicts of interest were disclosed.

2007; 26: 69-77.

14 Arihiro S, Kato T, Ito K, et al. Correlation between symptomatic improvement and quality of life in patients with reflux and dyspeptic symptoms. $J$ Clin Biochem Nutr 2012; 50: 205-210.

15 Kusano M, Shimoyama Y, Sugimoto S, et al. Development and evaluation of FSSG: frequency scale for the symptoms of GERD. J Gastroenterol 2004; 39: 888-891.

16 Verhaar HJ, Koele JJ, Neijzen T, Dessens JA, Duursma SA. Are arm span measurements useful in the prediction of osteoporosis in postmenopausal women? Osteoporos Int 1998; 8: 174-176.

17 Kusano M, Hashizume K, Ehara Y, Shimoyama Y, Kawamura O, Mori M. Size of hiatus hernia correlates with severity of kyphosis, not with obesity, in elderly Japanese women. J Clin Gastroenterol 2008; 42: 345-350.

18 Mizuta A, Adachi K, Furuta K, et al. Different sex-related influences of eating habits on the prevalence of reflux esophagitis in Japanese. J Gastroenterol Hepatol 2011; 26: 1060-1064.

19 Uno G, Amano Y, Yuki T, et al. Relationship between kyphosis and Barrett's esophagus in Japanese patients. Intern Med 2011; 50: 2725-2730.

20 Furukawa N, Iwakiri R, Koyama T, et al. Proportion of reflux esophagitis in 6010 Japanese adults: prospective evaluation by endoscopy. J Gastroenterol 1999; 34: 441-444.

21 Iwakiri R, Fujimoto K. Importance of vertebral fracture and body mass index in the pathogenesis of gastroesophageal reflux disease. Intern Med 2008; 47: 1551-1553.

22 Leidig-Bruckner G, Limberg B, Felsenberg D, et al. Sex difference in the validity of vertebral deformities as an index of prevalent vertebral osteoporotic fractures: a population survey of older men and women. Osteoporos Int 2000; 11: $102-119$.

23 Infantino M. The prevalence and pattern of gastroesophageal reflux symptoms in perimenopausal and menopausal women. J Am Acad Nurse Pract 2008; 20: 266-272.

24 Chen CL, Yi CH, Liu TT, Orr WC. Altered sensorimotor responses to esophageal acidification in older adults with GERD. Scand J Gastroenterol 
2010; 45: 1150-1155.

25 Lee J, Anggiansah A, Anggiansah R, Young A, Wong T, Fox M. Effects of age on the gastroesophageal junction, esophageal motility, and reflux disease. Clin Gastroenterol Hepatol 2007; 5: 1392-1398.

26 Hart R, Classen M. Complications of diagnostic gastrointestinal endoscopy.
Endoscopy 1990; 22: 229-233.

27 Takashima T, Yamaguchi K, Hara M, et al. Brief questioning by nursing staffs before endoscopic examination may not always pick up clinical symptoms of endoscopic reflux esophagitis. J Clin Biochem Nutr 2010; 46: 229-233. 